Microscopy

\section{Coming Events}

2018

255th ACS National Meeting

March 18-22, 2018

New Orleans, LA

www.acs.org/content/acs/en/meetings/nationalmeetings/

meetings.html

FOCUS ON MICROSCOPY 2018

March 25-28, 2018

Singapore, Republic of Singapore

www.focusonmicroscopy.org

2018 MRS Spring Meeting

April 2-6, 2018

Phoenix, AZ

www.mrs.org/spring2018

American Society for Investigative

Pathology

April 18-22, 2018

San Diego, CA

www.asip.org/meetings/EB_future.cfm

Histochemistry 2018

April 21-25, 2018

San Diego, CA

http://histochemicalsociety.org/Meetings-and-Courses/

Histochemistry-2018.aspx

EBSD 2018 - Electron Backscatter

Diffraction Conference

May 23-25, 2018

Ann Arbor, Ml

www.microbeamanalysis.org/topical-conferences/

ebsd-2018

Atom Probe Tomography and Microscopy

June 10-15, 2018

Gaithersburg, MD

www.nist.gov/news-events/events/2018/06/

atom-probe-tomography-and-microscopy-2018-aptm-2018

Microscopy \& Microanalysis 2018

August 5-9, 2018

Baltimore, MD

www.microscopy.org

2019

Microscopy \& Microanalysis 2019

August 4-8, 2019

Portland, OR

www.microscopy.org

2020

Microscopy \& Microanalysis 2020

August 2-6, 2020

Milwaukee, WI

www.microscopy.org

\section{1}

Microscopy \& Microanalysis 2021

August 1-5, 2021

Pittsburgh, PA

www.microscopy.org

\section{2}

Microscopy \& Microanalysis 2022

July 31-August 4, 2022

Portland, OR

www.microscopy.org

\section{3}

Microscopy \& Microanalysis 2023

July 24-28, 2023

Minneapolis, MN

www.microscopy.org

More Meetings and Courses

Check the complete calendar near the

back of this magazine.

\title{
Imaging In Vitro on the Nanometer Scale with Ultrasound
}

\author{
Stephen W. Carmichael* and James F. Greenleaf \\ Mayo Clinic, Rochester, MN 55905 \\ *carmichael.stephen@mayo.edu
}

There have been impressive advances in recent years in electron microscopy and light microscopy, but imaging molecular structures in vitro under physiological conditions has remained elusive. In order to provide spatial and temporal resolution on the nanoscale, fixation by chemical or freezing methods won't work, and introducing fluorescent or other tags would likely perturb the system. Scanning probe microscopy, such as atomic force microscopy (AFM), can provide high spatial resolution but is limited to identifying surface features and mechanical properties. During the past decade, acoustic-wave detection methods have been able to determine mechanical properties because elastic strain waves can travel through different materials without damaging them. Combining high-frequency ultrasonic waves and AFM, such that AFM can be used as a local mechanical detector of elastic waves, shows great promise for studying the nanomechanics of materials and subsurface imaging. However, imaging studies under physiological conditions have proven challenging because of acoustic dampening in aqueous media.

Recently Gajendra Shekhawat, Steven Dudek, and Vinayak Dravid have developed an ultrasonic bioprobe with nanometer-scale resolution for in vitro molecular imaging under physiological conditions while overcoming the limitation of ultrasound attenuation [1]. They conducted two proof-of-principle studies. In one they fabricated magnetic nanoparticles embedded within the core of silica core-shell nanoparticles with an average diameter of 30 to $40 \mathrm{~nm}$, and also they could identify the receptor layer coating, which was estimated to be about 5 to $10 \mathrm{~nm}$. With the ultrasound bioprobe they were able to image the magnetic nanoparticles beneath the surface of the shells. In the second system of live endothelial cells (ECs), they performed subcellular nanomechanical imaging.

Shekhawat et al. were able to overcome acoustic dampening within a fluid using an ultrasonic bioprobe controller with integrated feedback electronics. They used the

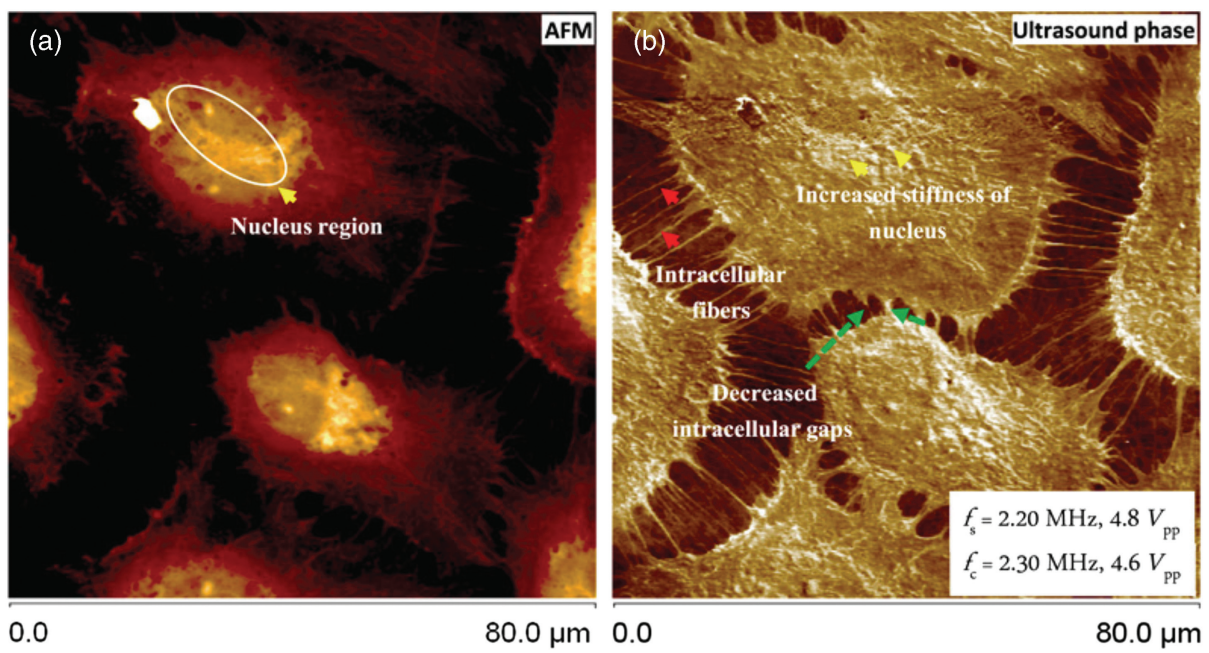

Figure 1: Live endothelial cells altered by addition of thrombin. (a) AFM topographical image and (b) ultrasound bioprobe phase image demonstrating remarkable contrast from intra-cellular fibers. Intracellular fibers are most clearly seen in the ultrasound phase image along with stretched gaps and sub-cellular phase contrast on the nuclei region of the cells. 


\section{Sample Preparation of Nanocomposites and Nanomaterials by Uhramiorotomy}

a Powerful Alternative

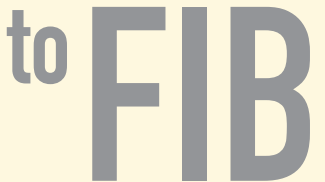

Join us at the EMS Microscopy Academy and learn the latest techniques to reveal internal structures of composites and polymers being investigated with transmission electron microscopy (TEM) and scanning transmission electron microscopy (STEM).

Sample preparation workflow will be illustrated using the Leica EM UC7 Ultramicrotome, its EM FC7 Cryochamber, and the RMC PowerTome Ultramicrotome. Differences between FIB (Focussed Ion Beam) and ultramicrotomy samples will also be covered.

\section{Who can benefit from this alternative?}

Composite and polymer research companies - especially from the automotive and aviation industries

Materials scientists already working with ultramicrotomy

FIB users preparing TEM lamellas

For more information, or to sign up for a workshop, please visit our website...

\section{www.emsdiasum.com}

DIATOME U.S.

P.0. Box $550 \bullet 1560$ Industry Rd.

Hatfield, Pa 19440

Tel: (215) 412-8390

Fax: (215) 412-8450

email: sgkcck@aol.com

\section{EMS Microscopy Academy}

P. . Box $550 \bullet 1560$ Industry Rd. • Hattield, Pa 19440 Tel: (215) 412-8400 • Fax: (215) 412-8450 Toll Free: 800-523-5874 • email: sgkcck@aol.com

Equipment used in this Technique...
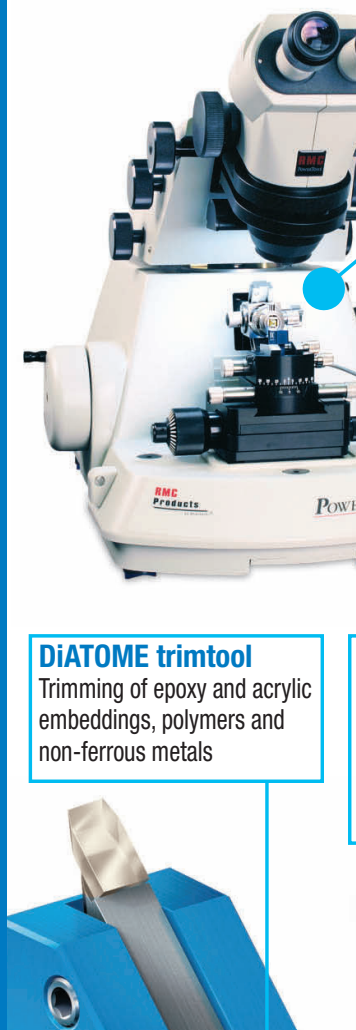

\section{RMC PowerTome} Ultramicrotomes

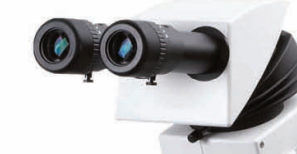

Leica EM UC7
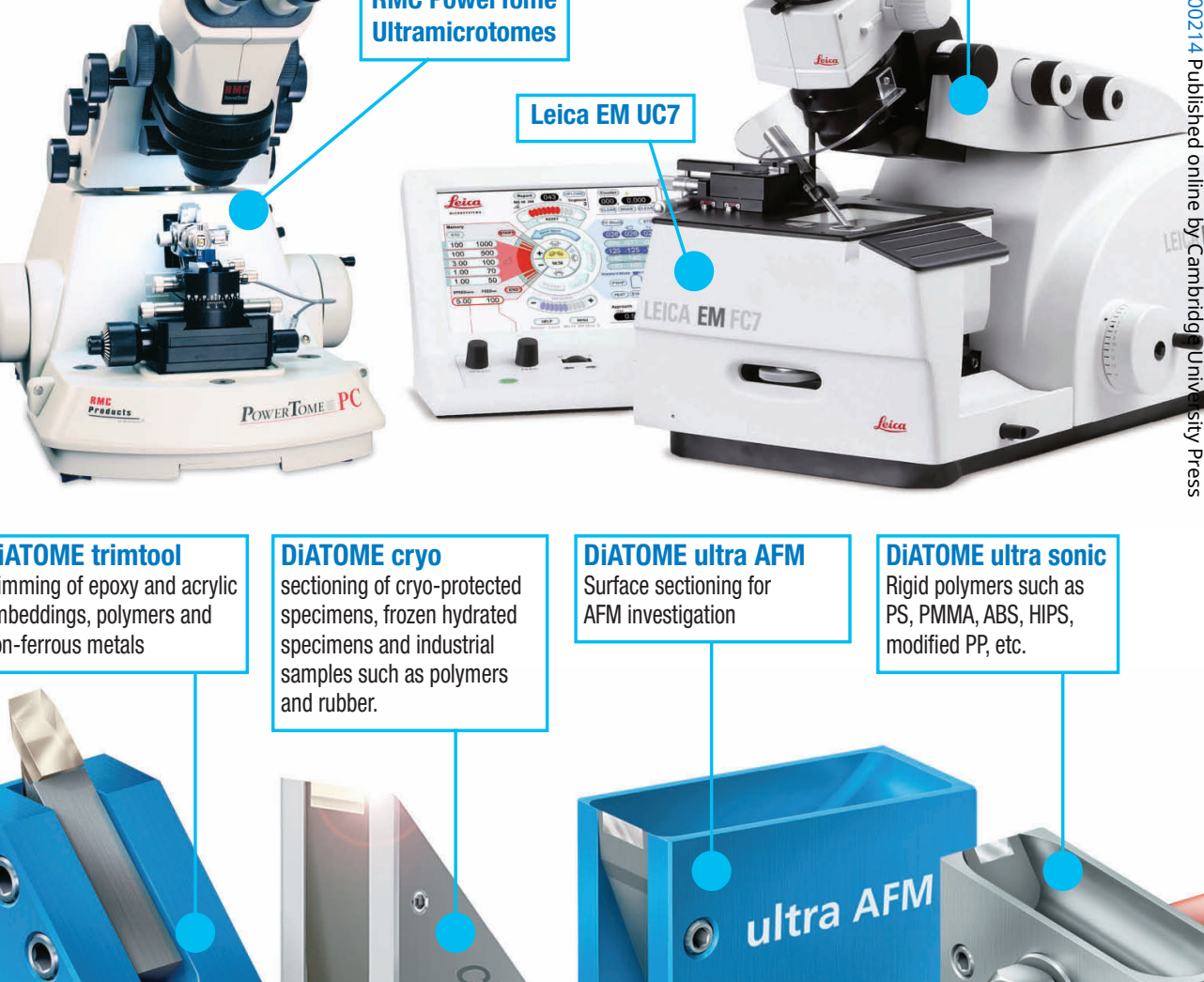

Q.

Applications... specimens and industrial samples such as polymers and rubber.
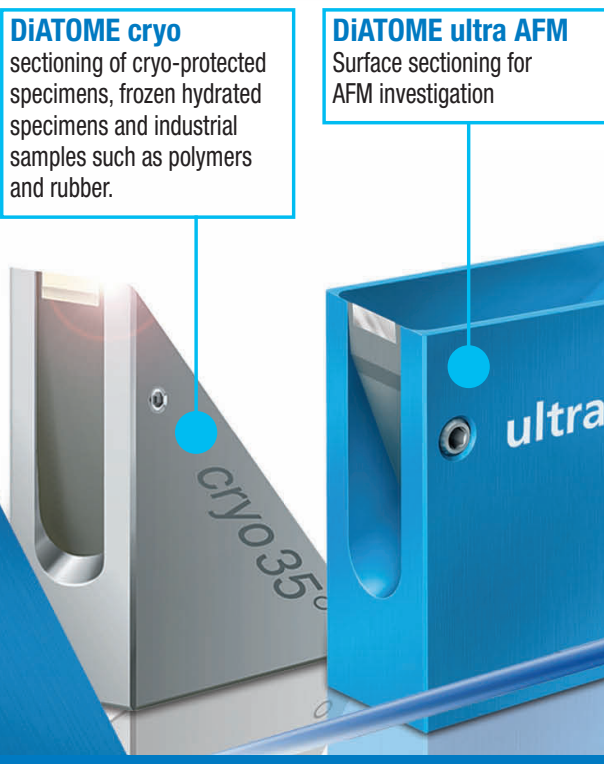

DiATOME ultra sonic Rigid polymers such as PS, PMMA, ABS, HIPS, modified PP, etc.
Zeolite USY30 Crystal morphology STEM analysis

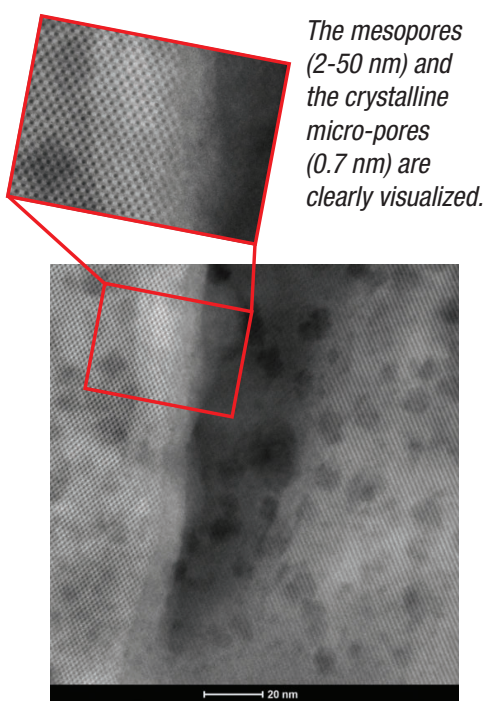

[110] Tom Willhammar, Sara Bals, EMAT Antwerpen
Epoxy loaded with amino-functionalized CNTs TEM analysis

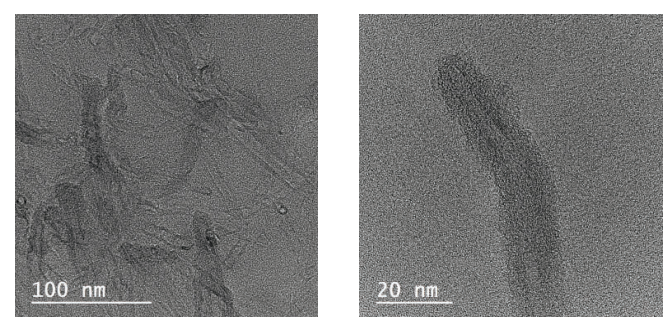

Good preservation of the interphase

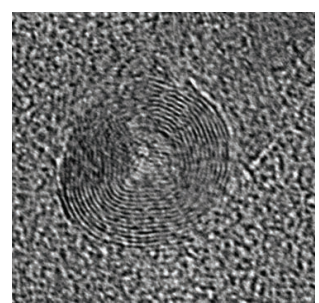

Mert Kurttepeli, Sara Bals, EMAT Antwerpen 
frequency shift of the received signal as evidence of altered stiffness. By controlling amplitude and detecting frequency, or phase, they produced an image dependent on the out-of-phase motion of the AFM probe.

The experimental model with ECs was selected because of possible application in the study of acute lung injury/acute respiratory distress syndrome (ALI/ARDS), a devastating complication of acute respiratory failure. Shekhawat et al. used an ultrasound bioprobe to directly measure the effect of the stimulating agent thrombin on the mechanics of intracellular fiber formation in these ECs. They demonstrated prominent cytoskeletal fibers in the phase image together with other subcellular features near the nuclei of these cells. Their results demonstrate the effectiveness of their technique to image the internal cellular structures and those along the cell periphery.

The development of an ultrasound bioprobe for intracellular and in vitro molecular imaging opens up new applications for in vitro subcellular biological imaging at high image resolution. If this technique can be independently replicated, it will fill a critical void in biology for non-destructive subsurface imaging with nanometer spatial resolution. [2]

\section{References}

[1] GS Shekhawat et al., Sci Adv (2017) 3: e1701176.

[2] The authors gratefully acknowledge Dr. Gajendra

Shekhawat for reviewing this article.

\section{WHAT DOES YOUR SEM 'SEE'?}

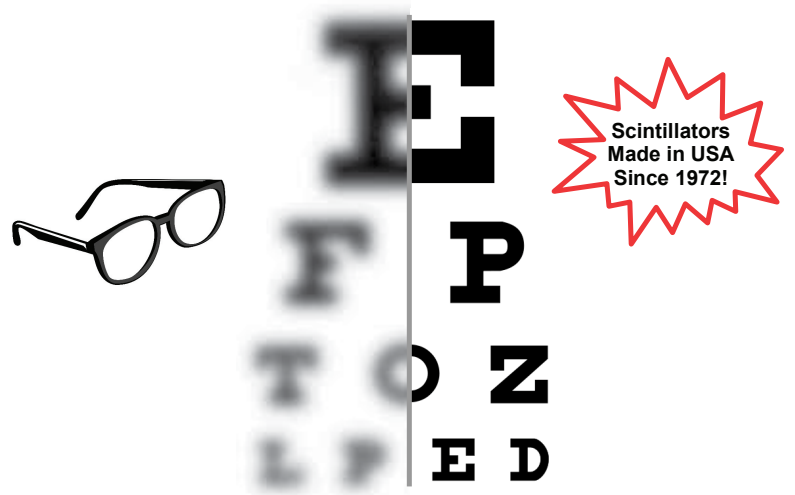

BUY A NEW SCINTILLATOR!

$\checkmark$ Common sizes in stock $\checkmark$ Easy To Install! $\checkmark$ Prices from $\$ 99$

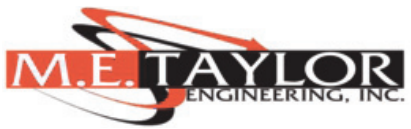

(301) 975-9798 • www.semsupplies.com

\section{Erase black squares with Evactron plasma cleaning}

New Evactron ${ }^{\circledR}$ E50 Turbo-Plasma ${ }^{\mathrm{TM}}$ cleaner for your SEM/FIB

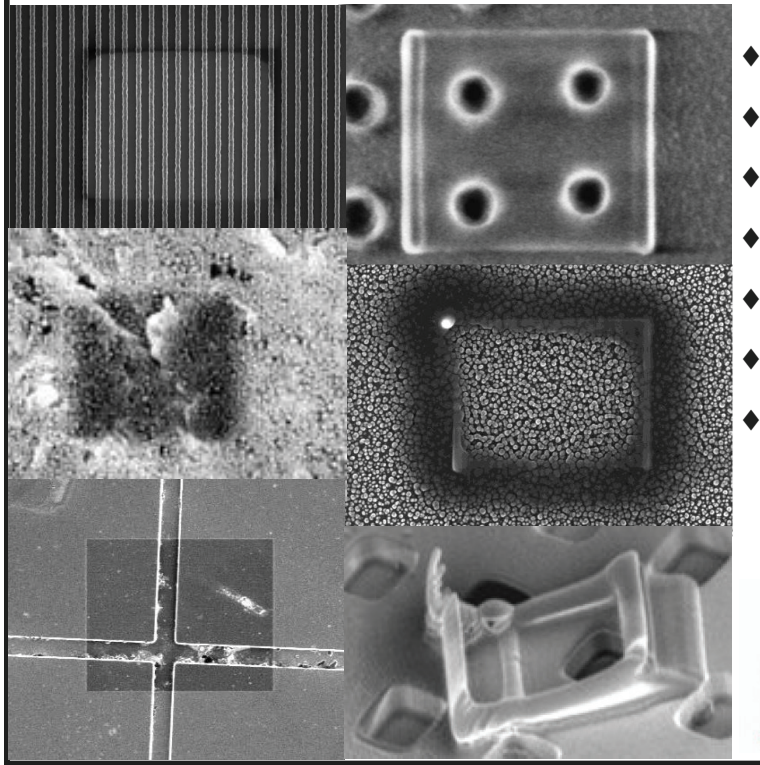

- New External Hollow Cathode Plasma Source

- 50 Watt max power for fast chemical etch

- No sputter etch damage or debris

- "POP'M" Ignition at high vacuum-no venting

- Push button or Android tablet operation

- Less downtime for cleaning and pumpdown

- Lowest cost + best performance = best value

Find The Fastest Way to Pristine

with the Evactron E50 De-Contaminator!

Evactron ${ }^{\circledR}$

By XEI Scientific
WWW.EVACTRON.COM 1-650-369-0133 
NEW YEMR
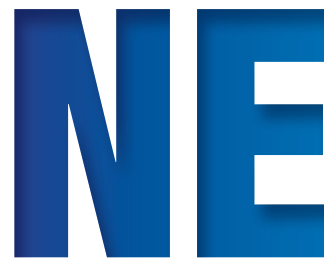

PRODUCTS

Contact us to receive your

EDEE GOP

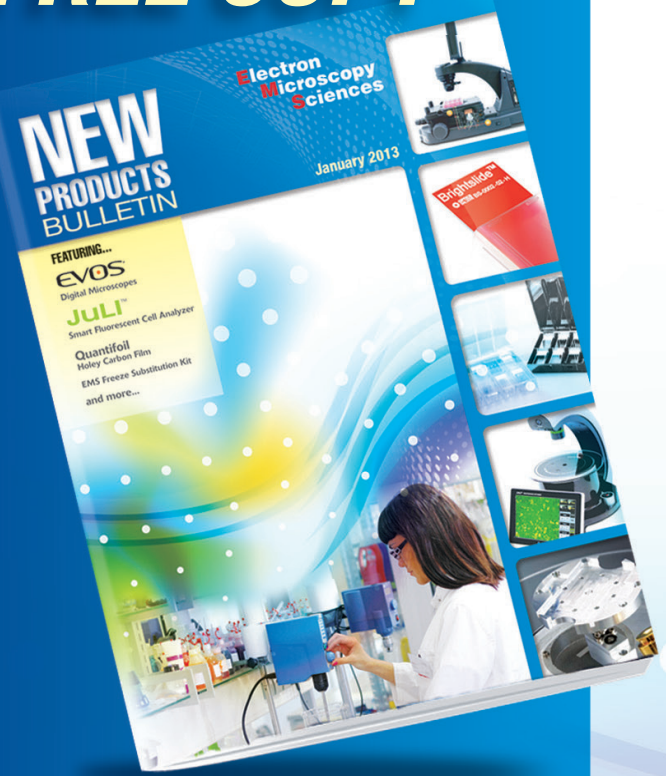

lectron

icroscopy

ciences

P.0. Box $550 \bullet 1560$ Industry Rd.

Hatfield, PA 19440

Tel: (215) 412-8400

Fax: (215) 412-8450

email: info@emsdiasum.com

\section{www.emsdiasum.com}

Our EMS New Products Bulletin for 2018 is now available and loaded with the latest innovative products for all fields of microscopy and general laboratory research.

CRYO-SEM PREPARATION • DIGITAL MICROSCOPES • SPECIMEN STAGES MICROSCOPE PLATFORMS • STAINING EQUIPMENT • VACUUM GREASES SLIDEPRINTING • HOLEY CARBON GRIDS • FLUORESCENCE VIEWING SYSTEMS FLUOROPOLYMER FILMS • CLEANING SUPPLIES • MAGNIFICATION TOOLS FLUORESCENCE ENHANCING SLIDES • FREEZE SUBSTITUTION KIT NANOMANIPULATION SYSTEMS • COMBINATION SCALES • INCUBATORS VACUUM PUMPS

COVERSLIPS 